\title{
Epithelial Splicing Regulatory Protein 1 Inhibits the Invasion and Metastasis of Lung Adenocarcinoma
}

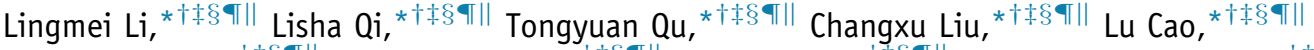

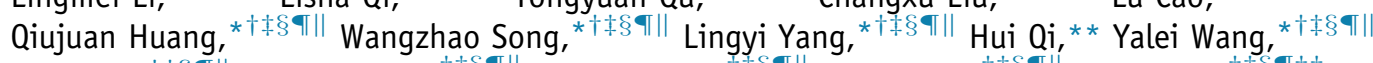

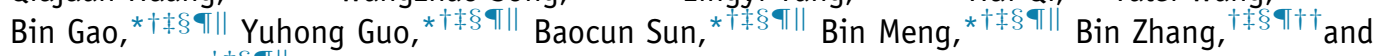 \\ Wenfeng Cao* ${ }^{*}+\delta \varangle \|$
}

From the Departments of Pathology* and Breast Cancer ${ }^{\dagger \dagger}$ and the National Human Genetic Resources Sharing Service Platform, ${ }^{\|}$Tianjin Medical University Cancer Institute and Hospital, Tianjin; the National Clinical Research Center for Cancer, ${ }^{\dagger}$ Tianjin; the Key Laboratory of Cancer Prevention and Therapy, ${ }^{\ddagger}$ Tianjin; the Tianjin's Clinical Research Center for Cancer ${ }^{\S}$ and the Key Laboratory of Breast Cancer Prevention and Therapy, ${ }^{\boldsymbol{\top}}$ Tianjin Medical University, Ministry of Education, Tianjin; and the Department of Intensive Care Medicine, ${ }^{* *}$ Tianjin Medical University General Hospital, Tianjin, People's Republic of China

\author{
Accepted for publication \\ April 17, 2018. \\ Address correspondence to \\ Wenfeng Cao, Ph.D., Depart- \\ ment of Pathology, Tianjin \\ Medical University Cancer \\ Institute and Hospital, Huan- \\ huxi Road, Hexi District, Tian- \\ jin, China, 300060. E-mail: \\ caowenfeng@tjmuch.com.
}

\begin{abstract}
Despite the development of various treatments, metastasis remains a significant problem with lung adenocarcinoma (ADC). The role and mechanism of epithelial splicing regulatory protein 1 (ESRP1), an epithelial-specific RNA binding protein, on promoting the invasion and metastasis of lung ADC remain to be fully elucidated. Immunohistochemical analysis in 125 human lung ADC tissue samples demonstrated that ESRP1 overexpression was inversely related to the presence of metastases, tumor size, and clinical stage of lung ADC. Impaired ESRP1 expression was also found to stimulate the invasion capacity of lung $A D C$ cells both in vitro and in vivo. Functionally, overexpression of the ZEB1 gene decreased ESRP1 expression, and knockdown of the ZEB1 gene caused increased ESRP1 expression. On the basis of a gene array analysis, the expression of ESRP1 was associated with the regulation of the extracellular matrix. The expression of CD44 and fibroblast growth factor receptor, representatives that interact with the extracellular matrix, was studied. The CD44 subtypes promoted lung ADC cell invasion by regulating matrix metalloproteinase 2 expression. In conclusion, ESRP1 inhibits the invasion and metastasis of lung $A D C$ and plays a role in regulating proteins involved in epithelial-to-mesenchymal transition. (Am J Pathol 2018, 188: 1882-1894; https://doi.org/10.1016/j.ajpath.2018.04.012)
\end{abstract}

Lung adenocarcinoma (ADC) is one of the most common cancers worldwide. ${ }^{1}$ Therefore, it is critical to understand the molecular mechanisms that regulate the metastasis of lung ADC. Alternative splicing, which is tightly regulated in a tissue- and cell-type-dependent fashion, is mediated by RNA binding proteins (RBPs). ${ }^{2,3}$ More than $90 \%$ of human genes can produce different isoforms through alternative splicing, which is often linked to various types of diseases, including cancer. ${ }^{4,5}$ A significant number of studies have identified important transcriptional regulators and largescale changes in gene expression programs that drive the phenotypic changes that occur during the epithelial-tomesenchymal transition (EMT).
Epithelial splicing regulatory protein 1 (ESRP1) is an RNA RBP that belongs to the heterogeneous nuclear ribonucleoprotein family. ${ }^{6}$ ESRP1 regulates hundreds of alternative splicing events and is associated with maintaining epithelial phenotypes. ${ }^{7,8}$ ESRP1 regulates epithelial-specific

Supported by National Natural Science Foundation of China grant 81402420 (W.C.), Tianjin Municipal Health Bureau Science and Technology Foundation grant 16KG125 (W.C.), Tianjin Natural Science Foundation grant 15JCQNJC12400 (W.C.), Tumor Translational Medicine Seed Fund of Tianjin Medical University Cancer Institute and Hospital grant 1510 (L.L.), and Tianjin Municipal Health Bureau grant 2015KZ08 (Y.W.).

Disclosures: None declared. 
splicing of the IgIII of fibroblast growth factor receptor (FGFR) 2 and generates the FGFR IIIb or the FGFR IIIc isoforms, which are mainly expressed in epithelial and mesenchymal tissues, respectively. FGFR IIIb is downregulated during EMT, whereas FGFR IIIc is up-regulated to confer sensitivity to FGF2, thus inducing even more aggressive phenotypes. ${ }^{9}$ Furthermore, a previous report demonstrated that the isoform switch CD44s was essential for cells to undergo EMT and was required for the formation of breast tumors that display EMT characteristics in mice. ${ }^{10}$ ESRP1 orchestrates an epithelial type of splicing regulatory program during transforming growth factor (TGF)$\beta 1$-induced EMT and regulates the expression of target genes that are involved in development, cell proliferation, differentiation, migration, apoptosis, invasion, and metastasis. ${ }^{11}$ Increasing evidence has suggested that ESRP1 is a master splice regulator implicated in alternative mRNA splicing programs important for EMT and tumor progression. Reinke et $\mathrm{al}^{11}$ reported that ESRP1 transcriptional repression by Snail is required for EMT to occur. However, little is known about ESRP1 expression and prognostic value in lung ADC and the molecular mechanisms underlying ESRP1 expression during EMT.

In this study, we investigated the expression of ESRP1 in patients with lung ADC and evaluated the correlation between ESRP1 expression and clinical data and the expression of EMT proteins. Using both loss- and gain-offunction approaches, we demonstrate that the downexpression of ESRP1 promotes the invasion and metastasis of lung ADC. ZEB1, a transcription factor, may regulate ESRP1 promoter transcriptional activity during EMT. Increasing our understanding of the role of ESRP1 during EMT could lead to more effective treatments of lung ADC metastasis.

\section{Material and Methods}

\section{Cell Culture and Reagents}

The lung ADC cell lines A549 and H1299 were obtained from the Type Culture Collection of the Chinese Academy of Sciences, Shanghai, China. The cells were cultured in RPMI 1640 medium supplemented with $10 \%$ fetal calf serum (FCS; HyClone, Logan, UT), $100 \mathrm{U} / \mathrm{mL}$ of penicillin, and $100 \mathrm{mg} / \mathrm{L}$ of streptomycin at $37^{\circ} \mathrm{C}$ in a $5 \% \mathrm{CO}_{2}$ humidified atmosphere. Logarithmic phase cells were used in the experiments. In some cases, 10\% FCS was changed to serum-free medium, depending on the experiment. The cells were treated with $5 \mathrm{ng} / \mathrm{mL}$ of TGF- $\beta 1$ for 24 hours. TGF- $\beta 1$ (AF-100-18B) was purchased from PeproTech (Rocky Hill, NJ).

\section{Clinical Samples}

A total of 125 lung ADC tissue samples and 21 sets of matched lung ADC primary foci and metastatic foci were collected from the Department of Pathology at Tianjin Medical University Cancer Institute and Hospital from January 2004 to December 2014. None of the patients had received chemotherapy or radiotherapy before their operation. The diagnosis of lung cancer was histopathologically confirmed. The protocols in this study were approved by the hospital's Protection of Human Subjects Committee.

\section{Immunohistochemistry}

For immunohistochemistry, paraffin-embedded tissues were cut into $4-\mu \mathrm{m}$ sections. The sections were deparaffinized, rehydrated, and stained with primary antibodies overnight at $4^{\circ} \mathrm{C}$. The slides were treated with a broad-spectrum secondary antibody and then treated with diaminobenzidine. Finally, the slides were counterstained with hematoxylin and visualized under a light microscope. Two pathologists (L.Q. and W.C.) independently quantified the expression of the antibody without knowledge of other clinical parameters. The intensity of ESRP1 staining was graded on a scale from 0 to 3 ( 0 for no staining, 1 for weak immunoreactivity, 2 for moderate immunoreactivity, and 3 for strong immunoreactivity). The percentage immunoreactivity was scored on a scale from 0 to 3 ( 0 for no positive cells, 1 for $<30 \%$ of cells being positive, 2 for $30 \%$ to $60 \%$ of cells being positive, and 3 for $>60 \%$ of cells being positive). The two scores were multiplied to obtain a composite expression score. The final expression level was classified as negative $(-)$ (score of 0 ), weakly positive (+) (score of 1 to 4 ), or strongly positive $(+++$ ) (score of 6 to 9). E-cadherin expression was considered positive if $>90 \%$ of tumor cells exhibited a staining pattern similar to that in normal epithelial cells. Vimentin expression was classified as positive when $>10 \%$ tumor cells were stained.

\section{Western Blot Analysis}

For Western blot analysis, cells were harvested in radioimmunoprecipitation assay 'lysis buffer. After incubation at $4^{\circ} \mathrm{C}$ for 30 minutes, the lysate was centrifuged at $15,000 \times g$ for 10 minutes at $4^{\circ} \mathrm{C}$. Protein concentration was determined using the bicinchoninic acid assay (Pierce, Rockford, IL). Samples were denatured in $5 \times$ SDS-PAGE buffer for 5 minutes at $95^{\circ} \mathrm{C}$ and subjected to $10 \%$ SDS-PAGE. The separated proteins were transferred to a polyvinylidene fluoride membrane (Millipore, Bedford, MA) for 2 hours at $4{ }^{\circ} \mathrm{C}$, blocked in $5 \%$ nonfat milk in phosphate-buffered saline plus Tween-20, and incubated with the appropriate primary antibodies. The following primary antibodies were used: E-cadherin (catalog number 3195s, Cell Signaling Technology, MA), N-cadherin (catalog number 4061s, Cell Signaling Technology), Snail (catalog number 5879s, Cell Signaling Technology), Twist (ab50581, Abcam, Cambridge, UK), ZEB-1 (catalog number 6935s, Cell Signaling Technology), ESRP1 (ab107278, Abcam), and $\beta$-actin (catalog number 3700s, Cell Signaling Technology). 
siRNA Duplexes, Plasmid Constructs, and Transient Transfection

siRNAs against ZEBI and ESRPI were purchased from Genechem (Shanghai, China) (GCPL37001, GIEL44382). Genomic DNA fragments of the human ZEB1, ESRP1, and $C D 44$ genes were generated by PCR and inserted into pcDNA3.1/myc-His vector. All constructs were sequenced to confirm their identity. For transfection, cells were plated at a density of $5 \times 10^{5}$ cells per well in 6 -well plates that contained serum-containing medium. When the cells were $80 \%$ confluent, $1 \times 10^{8}$ siRNAs were added to the medium for 12 hours. Plasmid DNA ( $3 \mu \mathrm{g})$ was then transfected into cells using FuGENE (Promega, Madison, WI) for 48 hours.

\section{Luciferase Assay and Chromatin Immunoprecipitation Assay}

Luciferase activity was measured using the Dual-Luciferase Reporter Assay System (Promega) as described by the manufacturer. A chromatin immunoprecipitation assay was performed using a commercial kit (17-10461, Millipore) according to the manufacturer's instructions.

\section{Invasion Assays}

Cell invasion assays were conducted using $8-\mu \mathrm{m}$ Transwell inserts (Corning Inc., Corning, NY) and 24-well BD BioCoat Matrigel Invasion Chambers (BD Biosciences, San Jose, CA) according to the manufacturer's recommendations. In brief, $3 \times 10^{4}$ cells were isolated and added to the upper chamber of a Transwell with RPMI 1640 medium. The invasion assay was performed using Matrigel-coated filters (BD Biosciences, Franklin Lakes, NJ). RPMI 1640 with $10 \%$ fetal bovine serum was added to the lower chamber, and the cells were allowed to incubate for 24 hours. After 24 hours of incubation, the membranes with the invaded cells were stained with hematoxylin, washed, and then mounted on slides. The entire membrane was then visualized under a light microscope $(\times 70$; Olympus, Tokyo, Japan). Data were expressed as the number of invaded cells per well. Each assay was conducted in triplicate and was repeated at least twice.

\section{RNA Isolation, cDNA Synthesis, and RT-PCR Analysis}

Total RNA was extracted from cells using the RNAiso Plus (Takara Biotechnology, Dalian, China) according to the manufacturer's instructions. Reverse transcription was performed with a high-capacity cDNA reverse transcribing according to the manufacturer's instructions. RT-PCR was performed using $2 \times$ PCR Solution Premix Taq (R004A, Takara Biotechnology), under the following conditions: $50^{\circ} \mathrm{C}$ for 30 seconds, $95^{\circ} \mathrm{C}$ for 15 minutes, 18 cycles of $94^{\circ} \mathrm{C}$ for 45 seconds, $68^{\circ} \mathrm{C}$ for 45 seconds, $72^{\circ} \mathrm{C}$ for 1 minute, $94^{\circ} \mathrm{C}$ for 45 seconds, and $55^{\circ} \mathrm{C}$ for 45 seconds.
CD44v: forward: 5'-ATGAGGGATATCGCCAAACAC$3^{\prime}$, reverse: 5'-TTCCTGCTTGATGACCTCGT-3'; CD44s: forward: 5'-GACATCACCCCAGCAACCCT-3', reverse: 5' GCTCCACCTTCTTGACTCCC-3'; ZEB1: forward: 5'-AGCAGTGAAAGAGAAGGGAATGC-3', reverse: $5^{\prime}$-GGTCCTCTTCAGGTGCCTCAG-3'; ESRP1: forward: 5'-TCCTGCTGTTCTGGAAAGTCG-3', reverse: 5'-TCCGGTCTAACTAGCACTTCGTG-3'; matrix metalloproteinase (MMP) 2: forward: 5'-GGCCTCGTATACCGCATCAATC-3', reverse: 5'-GGCCTCTCCTGACATTGACCTT-3'.

\section{Xenograft Mouse Model}

Forty mice (Wei Tong Li Hua Experimental Company, Beijing, China) were randomly divided into four groups and received $3 \times 10^{6} \mathrm{H} 1299$ cells by subcutaneous injection in the right groin or $5 \times 10^{6} \mathrm{H} 1299$ cells by injection through the tail vein. All animal care and procedures were approved by the Institutional Animal Use and Care Committee of Tianjin Medical University. Tumor volumes were measured 7 days after tumor cell injection.

\section{Hematoxylin and Eosin Staining}

Tissues were fixed in $10 \%$ neutral buffered formalin for 24 hours, embedded in paraffin wax, cut into $4-\mu \mathrm{m}$-thick sections, deparaffinized with xylene, and processed with a graded ethanol series. Sections were stained with hematoxylin and eosin and observed using an Olympus BX51 microscope.

\section{Statistical Analysis}

Data are presented as means \pm SD from at least three independent experiments. Fisher's exact tests were used to compare the groups using SPSS software version 22.0 (IBM, Chicago, IL). The Kaplan-Meier test was used to estimate the overall survival (OS) and recurrence-free survival (RFS). $P<0.05$ was considered significant.

\section{Results}

Correlation of ESRP1 Expression with Clinicopathologic Features of Lung ADC

To comprehend the expression patterns of ESRP1, the medical records of 125 patients with lung ADC were collected and reviewed. ESRP1 showed weak or absent expression in $76(60.8 \%)$ of the lung ADC tissue samples collected, and strong staining was shown in 49 cases $(39.2 \%)$. ESRP1 expression was significantly correlated with tumor size $(P<0.05)$, TNM stages $(P<0.05)$, metastasis $(P<0.05)$, and lymph node metastasis $(P<0.05)$ (Figure 1, A and $\mathrm{C}$ and Table 1). No significant association was found with age, sex, and histologic type. In addition, the expression of ESRP1 in tumor center cells was 
A

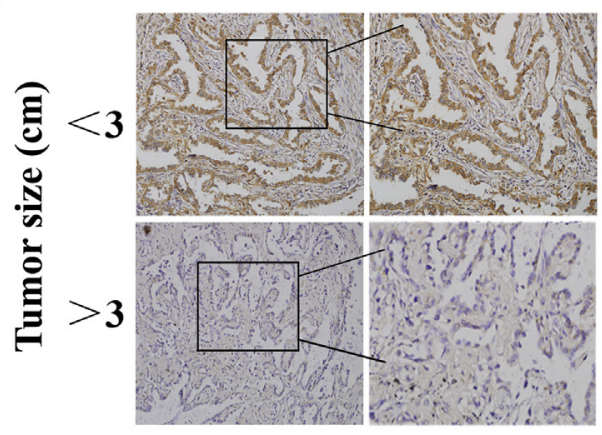

C

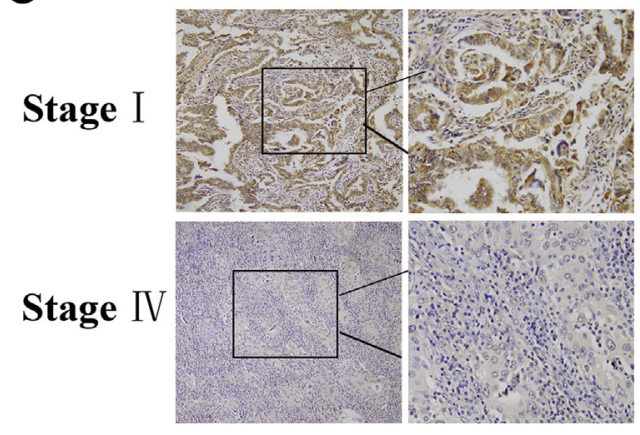

$\mathbf{E}$

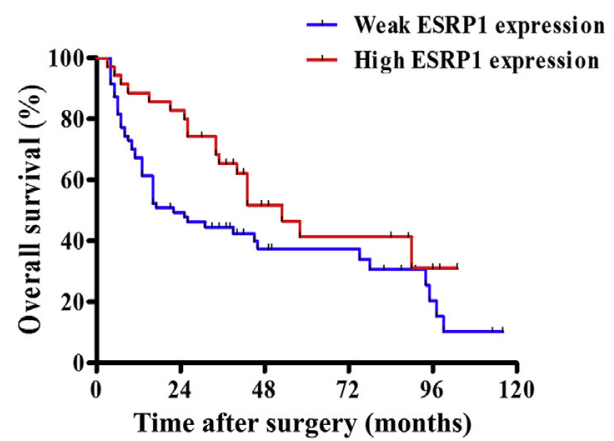

B

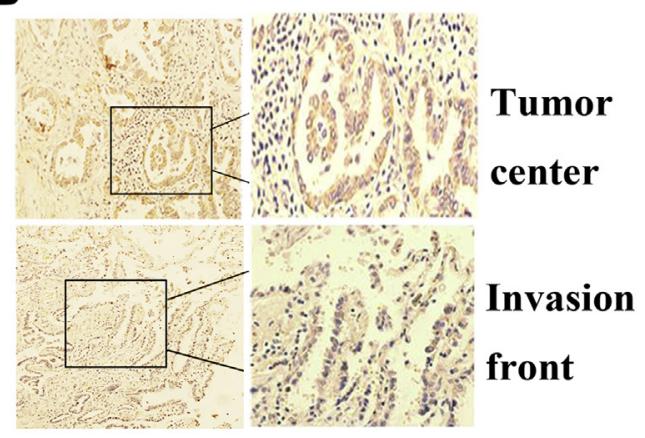

D
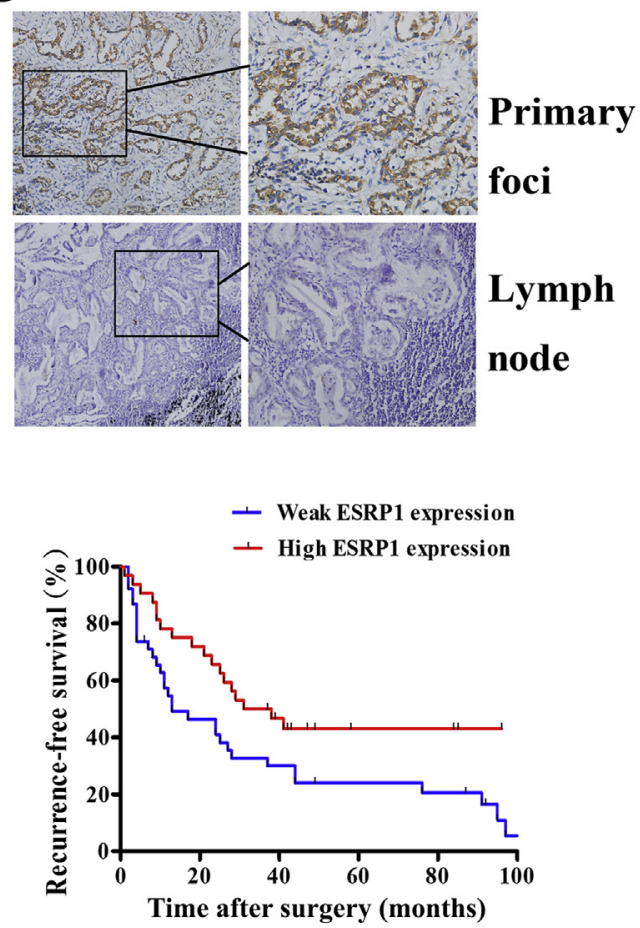

Figure 1 Correlation between epithelial splicing regulatory protein 1 (ESRP1) expression and clinicopathologic features of lung adenocarcinoma (ADC) cases. A-D: Immunohistochemical staining of ESRP1 shows different ESRP1 levels in lung ADC tumors of different tumor sizes (A), in the tumor center and the invasive front of the same lung ADC tissue sample (B), in lung ADC tumors at different stages (C), and in lung ADC primary foci and lymph node metastatic foci from the same patient (D). E: Kaplan-Meier curves displaying the overall survival of patients and recurrence-free survival of patients with high ESRP1 expression versus negative or low ESRP1 expression $(P<0.05$, log rank test). Original magnification, $\times 200$ (A-D).

stronger than the cells in the invasive front in the same case (Figure 1B).

Moreover, in the 21 matched lung ADC cases, the expression levels of ESRP1 in the lymph node metastatic tissues were markedly decreased compared with the lung ADC primary tissues (Figure 1D and Table 2). This finding indicates that the down-regulation of ESRP1 may be involved in the invasion process of lung ADC. Moreover, increased ESRP1 expression may be associated with a significantly better OS and RFS than those with weak ESRP1 expression ( $P=0.044$ for OS, $P=0.034$ for RFS) (Figure 1E). In univariate survival analysis, papillary predominant type, TNM stages, lymph node metastasis, and ESRP1 expression were prognostic factors. In multivariate survival analysis, papillary predominant type, TNM stages, and ESRP1 expression were independent prognostic factors (Table 3). All the above results suggest that ESRP1 plays an important role in lung ADC progression.

\section{ESRP1 Silencing Promotes Cell Invasion and Migration of Lung ADC Cells}

To assess the effect of ESRP1 on the invasion ability of lung ADC cells, three siRNAs [small interfering (si) ESRP1-1, siESRP1-2, and siESRP1-3] were used to knockdown ESRP1. An si control was used as a negative control. Subsequently, siESRP1-2, which was the most efficient to silence ESRP1 (Figure 2A), increased lung ADC cell invasion in treated cells (Figure 2B). In addition, an ESRP1 expression vector was transfected into A549 and H1299 
Table 1 Correlation between Epithelial Splicing Regulatory Protein 1 (ESRP1) and Clinicopathologic Characteristics of Lung Adenocarcinoma

\begin{tabular}{|c|c|c|c|c|c|}
\hline \multirow[b]{2}{*}{ Variable } & \multirow[b]{2}{*}{ Total } & \multicolumn{2}{|c|}{ ESRP1 expression } & \multirow[b]{2}{*}{$\chi^{2}$} & \multirow[b]{2}{*}{$P$ value } \\
\hline & & $-/+$ & ++ & & \\
\hline \multicolumn{6}{|l|}{ Age, years } \\
\hline$>60$ & 58 & $37(63.8)$ & $21(36.2)$ & & \\
\hline \multicolumn{6}{|l|}{ Sex } \\
\hline Male & 63 & $40(63.5)$ & $23(36.5)$ & 0.386 & 0.331 \\
\hline$\leq 3$ & 64 & $46(71.9)$ & $18(28.1)$ & 6.749 & 0.008 \\
\hline$>3$ & 61 & $30(49.2)$ & $31(50.8)$ & & \\
\hline \multicolumn{6}{|l|}{ Histologic type } \\
\hline Lepidic predominant & 26 & $20(76.9)$ & $6(23.1)$ & 17.433 & 0.180 \\
\hline Acinar predominant & 51 & $36(70.6)$ & $15(29.4)$ & & \\
\hline $\mathrm{I}$ & 29 & $14(48.3)$ & $15(51.7)$ & 10.646 & 0.014 \\
\hline II & 27 & $13(48.1)$ & $14(51.9)$ & & \\
\hline III & 38 & $23(60.5)$ & $15(39.5)$ & & \\
\hline IV & 31 & $26(83.9)$ & $5(16.1)$ & & \\
\hline \multicolumn{6}{|l|}{ Metastasis } \\
\hline Present & 31 & $26(83.9)$ & $5(16.1)$ & 9.206 & 0.002 \\
\hline Absent & 94 & $50(53.2)$ & $44(46.8)$ & & \\
\hline \multicolumn{6}{|l|}{ Lymph metastasis } \\
\hline Present & 74 & $50(67.6)$ & $24(32.4)$ & 3.485 & 0.047 \\
\hline Absent & 51 & $26(51.0)$ & $25(49.0)$ & & \\
\hline
\end{tabular}

$P$ values in bold are significant.

cells, making the cells stably express ectopic ESRP1 (Figure 2C). Increased expression of ESRP1 effectively inhibited the invasion of A549 and H1299 cells (Figure 2D).

Knockdown of ESRP1 led to the invasion of lung ADC cells in vitro; therefore, the role of ESRP1 expression was further assessed in vivo. H1299 cells were transfected with siESRP1 or si control, and the expression of ESRP1 was determined by Western blotting (Figure 3A). These H1299 cells were then subcutaneously injected into nude mice, and the size of the lung ADC was observed regularly. siESRP12 markedly retarded the growth of lung ADC cells in nude mice compared with controls $(P<0.05)$ (Figure 3B). Tumors obtained with control and siESRP1-2-treated cells

Table 2 Epithelial Splicing Regulatory Protein 1 (ESRP1) Expression in Matched Lung Adenocarcinoma Primary Foci and Metastatic Foci in Lymph Nodes

\begin{tabular}{llrrll}
\hline & \multicolumn{4}{l}{ ESRP1 expression, no. (\%) } & \\
\cline { 2 - 5 } Variable & Total & \multicolumn{1}{c}{$/+$} & \multicolumn{1}{c}{++} & \multicolumn{1}{c}{$\chi^{2}$} & $P$ value \\
\hline Primary foci & 21 & $8(38.1)$ & $13(61.9)$ & 6.222 & $\mathbf{0 . 0 2 8}$ \\
Metastatic foci & 21 & $16(76.2)$ & $5(23.8)$ & & \\
Total & 42 & $24(57.1)$ & $18(42.9)$ & & \\
\hline
\end{tabular}

$P$ values in bold are significant. were subsequently tested for the expression level of ESRP1. The treatment suppressed the expression of ESRP1 (Figure 3C). Furthermore, following the tail vein injection of siESRP1-2 and si control, liver tissue was histologically examined; the siESRP1-2 group had more liver metastasis nodes $(P<0.05)$ compared with the si control group (Figure 3D). Taken together, these results reveal that the down-regulation of ESRP1 promotes the invasion and migration of lung ADC cells in vitro and in vivo.

\section{ESRP1 Silencing Promotes EMT of Lung ADC Cells}

Next, ESRP1 and EMT marker proteins E-cadherin and vimentin were immunohistochemically stained in 60 lung ADC tissues to further assess the role of ESRP1 during EMT. The ESRP1-negative group showed higher vimentin expression and lower E-cadherin expression, whereas this ratio was reversed in the groups strongly positive for ESRP1 (Figure 4A). The ESRP1-positive group had higher Ecadherin expression $(P<0.05)$ and lower vimentin expression $(P<0.05)$ than the weak and negative groups, thereby confirming that ESRP1 is involved in the regulation of EMT of lung ADC cells (Table 4). Moreover, the expression of ESRP1 was investigated during EMT in lung 
Table 3 Univariate and Multivariate Cox Proportional Hazards Regression Analyses for Overall Survival in Lung Adenocarcinoma

\begin{tabular}{|c|c|c|c|c|}
\hline \multirow[b]{2}{*}{ Variable } & \multicolumn{2}{|l|}{ Univariate analysis } & \multicolumn{2}{|l|}{ Multivariate analysis } \\
\hline & $\mathrm{HR}(95 \% \mathrm{CI})$ & $P$ value & $\mathrm{HR}(95 \% \mathrm{CI})$ & $P$ value \\
\hline Sex, male versus female & $0.894(0.552-1.447)$ & 0.648 & $0.842(0.497-1.0042)$ & 0.842 \\
\hline Tumor size, $\leq 3$ versus $>3 \mathrm{~cm}$ & $0.989(0.612-1.599)$ & 0.965 & $0.937(0.541-1.622)$ & 0.937 \\
\hline \multicolumn{5}{|l|}{ Histologic style } \\
\hline Acinar predominant & $1.372(0.357-5.275)$ & 0.645 & $2.889(0.630-13.244)$ & 0.172 \\
\hline Micropapillary predominant & $1.504(0.334-6.775)$ & 0.595 & $3.297(0.635-17.116)$ & 0.156 \\
\hline Papillary predominant & $4.957(1.096-22.412)$ & 0.038 & $5.716(1.174-27.821)$ & 0.031 \\
\hline TNM stages, I versus II versus III versus IV & $1.725(1.350-2.204)$ & 0.020 & $1.771(1.215-2.581)$ & 0.003 \\
\hline Metastasis, present versus absent & $1.599(0.961-2.658)$ & 0.071 & $0.667(0.357-1.247)$ & 0.205 \\
\hline Lymph metastasis, present versus absent & $3.214(1.878-5.499)$ & 0.030 & $3.067(0.540-6.004)$ & 0.205 \\
\hline
\end{tabular}

$P$ values in bold are significant.

$H R$, hazard ratio.

ADC cell lines. EMT was induced by TGF- $\beta 1$, and downregulation of ESRP1 and the known markers for EMT was subsequently observed (Figure 4B). To clear the transcriptional regulation of the ESRP1 gene during EMT, the expression of Snail, Twist, and ZEB1 was analyzed at different time points during EMT. Western blotting analysis of A549 and H1299 cells revealed that the expression of the transcription factor ZEB1 was significantly correlated with ESRP1 expression. In contrast, no such trends were observed with the expression of Snail and Twist (Figure 4C). Next, ZEBI and ESRPI gene expression was verified by RT-PCR. On treatment with TGF- $\beta 1$, an increase in ZEB1 expression and a decrease in ESRP1 expression was observed (Figure 4D).

Then, A549 and H1299 cells were transiently transfected with a ZEB1 overexpression construct. The expression of ZEB1 and ESRP1 was examined by Western blot analysis, and an increase in ZEB1 expression and a decrease in ESRP1 expression was observed (Figure 5A). This finding suggests that ZEB1 was related to the down-regulation of ESRP1 during EMT in lung ADC cells. To verify further the association between ZEB1 and ESRP1, ESRP1 expression was analyzed in cells treated with siZEB1. The ZEB1 gene was silenced using three different siRNAs: siZEB1-1, siZEB1-2, and siZEB1-3 (Figure 5B). ZEB1 expression was inhibited after the treatment of A549 and H1299 cells with siZEB1, with siZEB1-1 showing the most significant reduction in ZEB1 expression. Subsequent experiments used siZEB1-1 to knockdown ZEB-1 in both cell lines, which led to an increase in ESRP1 expression. In addition, transfection of A549 and H1299 cells with siZEB1 reversed the effects of TGF- $\beta 1$ on the expression of ESRP1, suggesting that ZEB1 is essential to TGF- $\beta 1$-induced down-regulation of ESRP1 in lung ADC cells (Figure 5C).

To investigate whether ZEB1 directly binds to the E-boxes on the ESRP1 promoter, a chromatin immunoprecipitation assay was performed in A549 and H1299 cells with and without TGF- $\beta 1$. The E-boxes immunoprecipitated by a commercially available anti-ZEB1 antibody were detected by PCR. The PCR products of intergenic regions were used as a negative control. After treatment with TGF- $\beta 1$, an enrichment of the interactions between ZEB1 and the DNA fragments was observed on the ESRP1 promoter in A549 and H1299 cells compared with the control. This finding suggests that, after TGF- $\beta 1$ treatment, ZEB1 regulates ESRP1 by binding to E-boxes located within the ESRPI promoter (Figure 5D). To determine whether the binding of ZEB1 to the E-box-containing regions represents a functional action for the activation of ESRP1 transcription, a luciferase reporter vector was constructed. Analysis of ESRP1 promoter activity was performed by transfecting A549 and H1299 cells with the promoter fragments of ESRP1 inserted into a pGL4.17 plasmid. The ZEB1-overexpressing plasmid (pcDNA3.1ZEB1) or control vector (pcDNA3.1) was then cotransfected with pGL4.17-ESRP1 promoter into A549 and H1299 cells. The renal plasmid was used to normalize transfection efficiency. After incubation for 48 hours, cells were harvested for a dual luciferase assay. The activity of the ZEB1-overexpressing group was lower than that of the negative control (Figure 5E). These results demonstrate that ZEB1 directly binds to the ESRP1 promoter and suppresses the transcription of ESRPI in lung ADC cells.

Decreased ESRP1 Expression Leads to the Alternative Splicing of CD44 and FGFR and Increased Migration and Invasion of Lung ADC Cells

Efficient invasion and metastasis require tumor cells to alter ECM composition to facilitate cells to enter the surrounding tissues. Given this fact, the representative of ECM receptors, 
A

A549

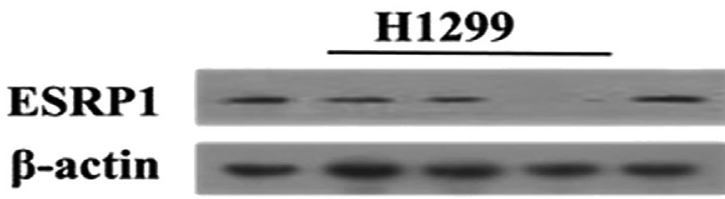<smiles>[CH][CH]</smiles><smiles>[CH]C1[CH]CC1</smiles><smiles>C[Si]1[C]C=C1</smiles>

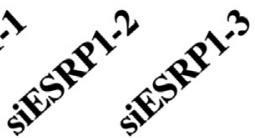

B

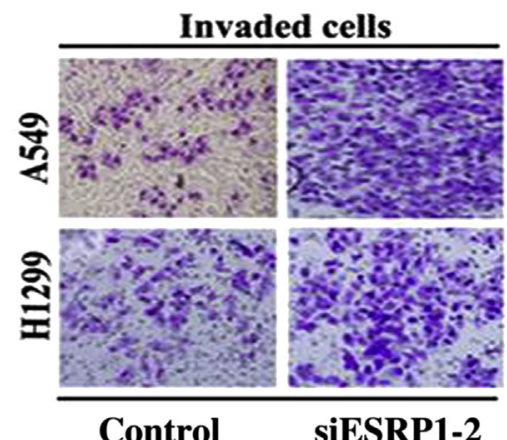

C
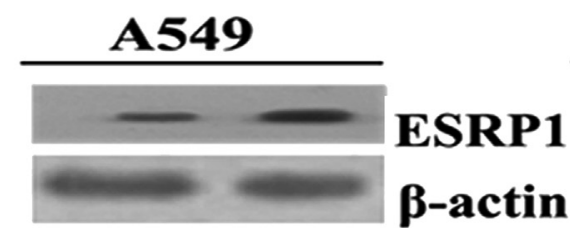

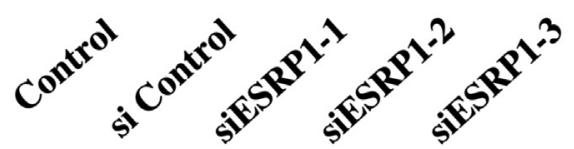

- Control
siESRP1-2

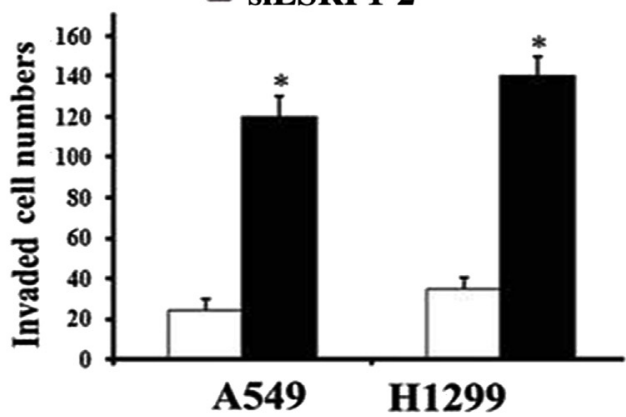

H1299

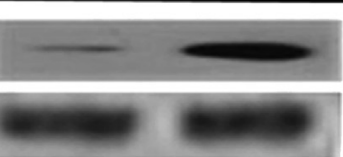

\section{Control ESRP1 vector Control ESRP1 vector}

D

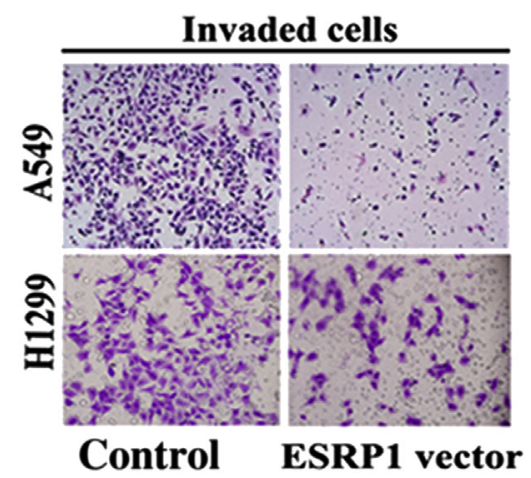

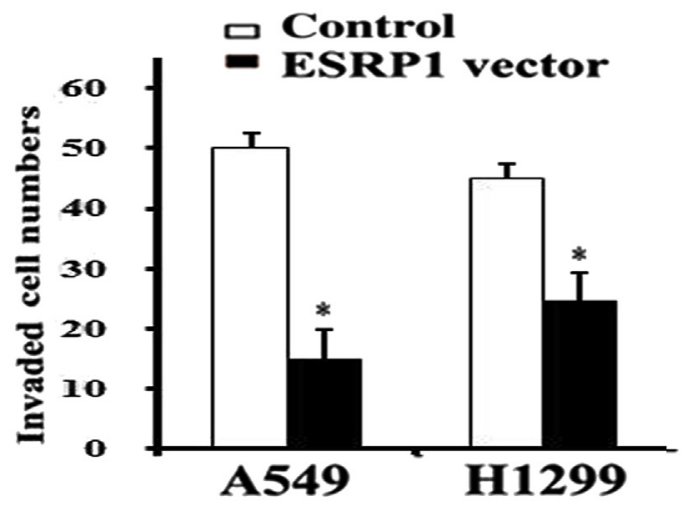

Figure 2 Epithelial splicing regulatory protein 1 (ESRP1) silencing promotes cell invasion and migration of lung adenocarcinoma (ADC) cells. A: Western blot assay measuring the expression of ESRP1 in A549 and H1299 cells treated with three siRNAs: small interfering (si) ESRP1-1, siESRP1-2, and sdESRP1-3. $\beta$-actin was used as a loading control. B: Transwell assay showing invasion of cells treated with control siRNA and siESRP1-2. C: Western blot assay measuring the expression of ESRP1 in A549 and H1299 cells treated with the control vector and the ESRP1 vector. $\beta$-actin was used as a loading control. D: Transwell assay showing invasion of cells treated with the control vector and the ESRP1 vector. Data are expressed as means \pm SD of three independent experiments $(\mathbf{B}$ and $\mathbf{D})$. The axis represents the fold change in the number of cells (B and $\mathbf{D})$. Data are expressed as means \pm SD of 3 independent experiments (B and $\mathbf{D})$. ${ }^{*} P<0.05$ versus control. Original magnification, $\times 100$ (B and $\left.\mathbf{D}\right)$.

CD44 and FGFR, whose transcripts were alternatively spliced after ESRP1 expression, were further studied.

The effect of the ectopic expression of ESRP1 on the expression of FGFR2 alternative splicing was then examined in lung ADC cells. FGFR2 IIIc was abundant in
TGF- $\beta 1-$ treated cells that expressed low FGFR2 IIIb levels, but its expression decreased in TGF- $\beta 1$-treated cells overexpressing ESRP1 and expressing relatively high levels of FGFR2 IIIb (Figure 6A). Alternative splicing of FGFR2 mRNA generates the FGFR2 IIIb isoform, which selectively 
A

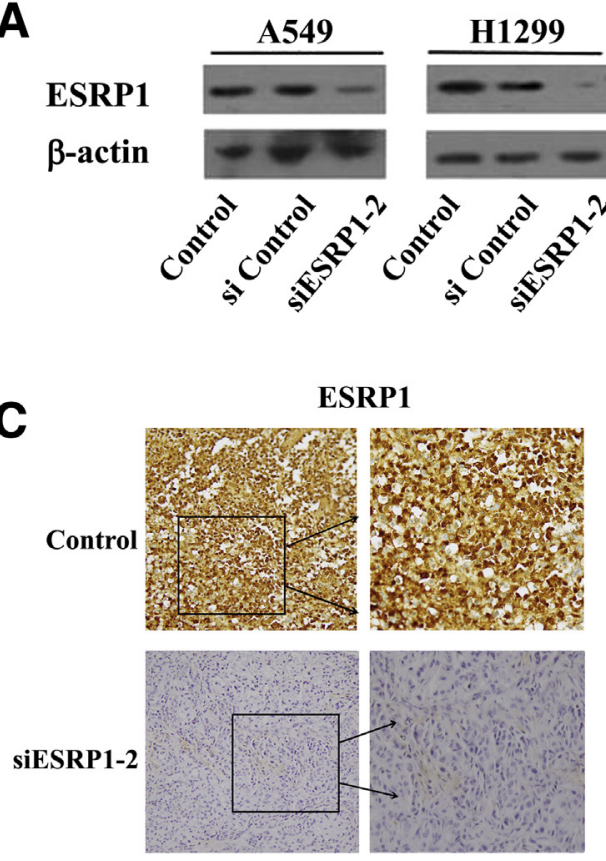

B
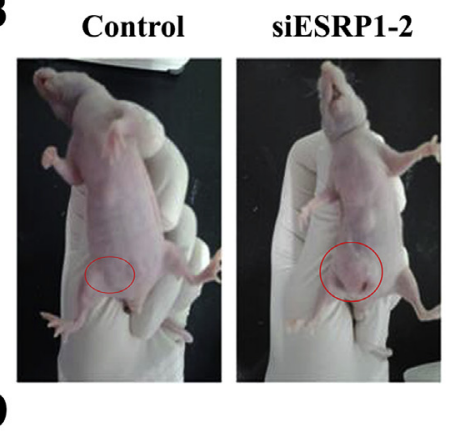

\begin{tabular}{cccc}
\hline Control & siESRP1-2 \\
$(n=10)$ & $(n=10)$
\end{tabular}$\quad P$

Tumor

volume $\quad 2.767 \quad 7.375 \quad 0.006$

D

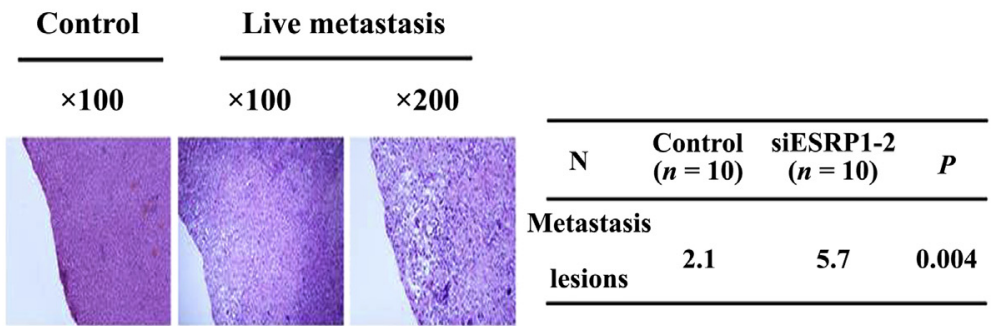

Figure 3 Down-regulation of epithelial splicing regulatory protein 1 (ESRP1) promotes the invasion and migration of lung adenocarcinoma cells in vivo. A: Western blot analysis measuring the expression of ESRP1 in A549 and H1299 cells treated with small interfering (si) ESRP1-2. $\beta$-actin was used as a loading control. B: Representative images of tumors formed in nude mice injected subcutaneously with $\mathrm{H} 1299$ control cells and siESRP1-2-treated cells (red circles mark the size of the tumor.). C: The expression of ESRP1 in control cells and siESRP1-2-treated cells. D: Mice injected with H1299 control cells and siESRP1-2-treated cells show liver metastasis. Sections were stained with hematoxylin and eosin. Original magnification, $\times 200$ (C and D).

binds to fibroblast growth factor (FGF) 7 with high affinity, or the FGFR2 IIIc isoform, which selectively binds to FGF4. The concentration of FGF4 in the cell culture medium after the above treatment further suggests that FGFR2 was alternatively spliced after ESRP1 overexpression (Figure 6B).

RT-PCR was used to determine the mRNA levels of ESRP1, CD44v, and CD44s after cells were treated

A
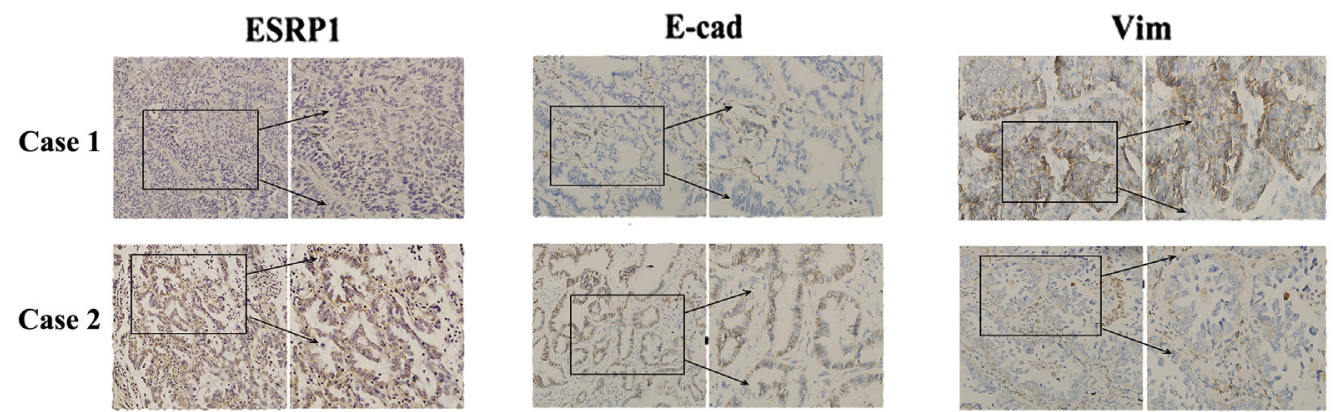

B

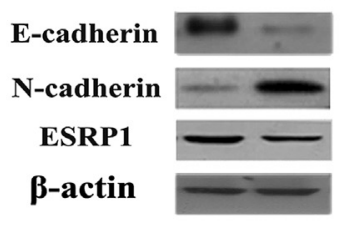

A549

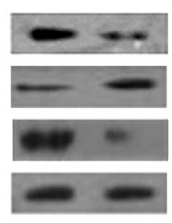

H1299
C

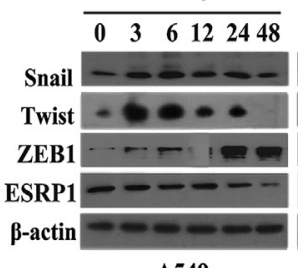

A549

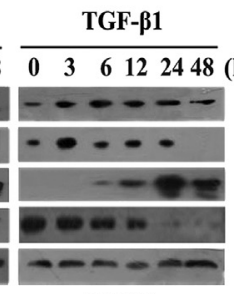

H1299

D

Control TGF- $\beta 1$ Control TGF- $\beta 1$

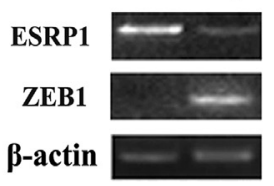

A549

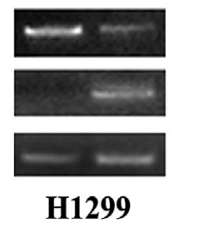

Figure 4 Epithelial splicing regulatory protein 1 (ESRP1) silencing promotes the induction of epithelial-to-mesenchymal transition (EMT). A: Immunohistochemical staining of E-cadherin (E-cad) and vimentin (Vim) in the negative and positive groups with ESRP1 levels in human lung adenocarcinoma tissue samples. B: Western blot analysis of EMT-related proteins and ESRP1 in A549 and H1299 cells treated with $5 \mathrm{ng} / \mathrm{mL}$ of transforming growth factor (TGF)- $\beta 1$. $\beta$-actin was used as a loading control. C: Western blot analysis measuring the expression of EMT transcription factors (Snail, Slug, and Twist) and ESRP1 in A549 and H1299 cells treated with 5 $\mathrm{ng} / \mathrm{mL}$ of TGF- $\beta 1$ at different times $(0,3,6,12,24$, and 48 hours). $\beta$-actin was used as a loading control. D: RT-PCR analysis shows the mRNA level of ESRP1 and ZEB1 after treatment with $5 \mathrm{ng} / \mathrm{mL}$ of TGF- $\beta 1$. $\beta$-actin was used as a loading control. Original magnification, $\times 40$ (A, main images); $\times 100$ (A, boxed areas enlarged). 
Table 4 Correlation between Expression of Epithelial Splicing Regulatory Protein 1 (ESRP1) and Epithelial-to-Mesenchymal Transition-Association Proteins

\begin{tabular}{|c|c|c|c|c|c|}
\hline \multirow[b]{2}{*}{ Variable } & \multicolumn{3}{|c|}{ ESRP1 expression, no. (\%) } & \multirow[b]{2}{*}{$\chi^{2}$} & \multirow[b]{2}{*}{$P$ value } \\
\hline & Total & $-/+$ & ++ & & \\
\hline E-cadherin & & & & 7.260 & 0.012 \\
\hline- & $10(16.7)$ & $7(70.0)$ & $3(30.0)$ & & \\
\hline+ & $50(83.3)$ & $13(26.0)$ & $37(74.0)$ & & \\
\hline Vimentin & & & & 7.212 & 0.013 \\
\hline- & $52(86.7)$ & $14(26.9)$ & $38(73.1)$ & & \\
\hline+ & $8(13.3)$ & $6(75.0)$ & $2(25.0)$ & & \\
\hline
\end{tabular}

$P$ values in bold are significant.

with $5 \mathrm{ng} / \mathrm{mL}$ of TGF- $\beta 1$ for $0,2,4,8,12,24,36$, and 48 hours. ESRP1 expression drastically decreased, and this down-regulation facilitated the production of CD44s. (Figure 7A). After cells were transfected with the ESRP1 vector and treated with TGF- $\beta 1$ for 24 hours, the level of
$\mathrm{CD} 44 \mathrm{v}$ markedly recovered, whereas the expression of CD44s was suppressed (Figure 7B). This finding confirmed that the overexpression of ESRP1 effectively retarded an isoform switch from CD44v to CD44s. Conversely, knockdown of ESRP1 in A549 and H1299 cells induced a switch in the expression of CD44v to CD44s (Figure 7C). These results indicate that ESRP1 regulates the switch between $\mathrm{CD} 44 \mathrm{v}$ and $\mathrm{CD} 44 \mathrm{~s}$ and increases the level of CD44s in lung ADC cells. The effect of CD44s on the expression of some proteins critical for cell invasion, including MMP-2 and MMP-9, was then examined using PCR. CD44s overexpression increased MMP-2 levels in A549 and H1299 cells, whereas the level of MMP-9 was unchanged, suggesting that MMP-2 is involved in CD44smediated lung ADC cell invasion (Figure 7, D and E). The role of CD44s on the invasion and migration of lung ADC cells was next determined. The number of CD44s vector transfected-cells invaded through a chamber was markedly increased compared with control cells (Figure 7F).
A

Control ZEB1 Control ZEB1 vector vector vector vector

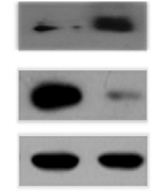

A549

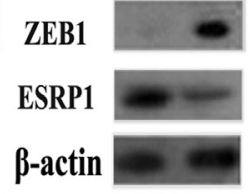

H1299
B

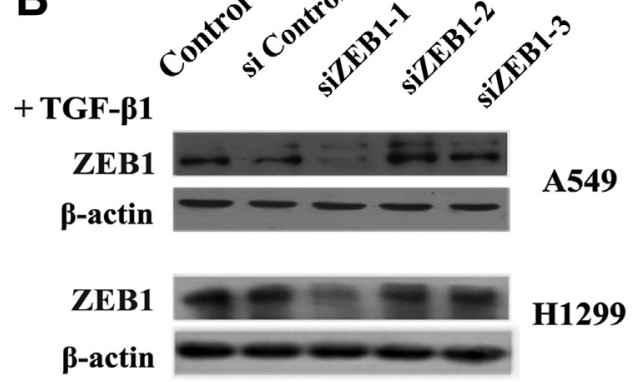

D

C

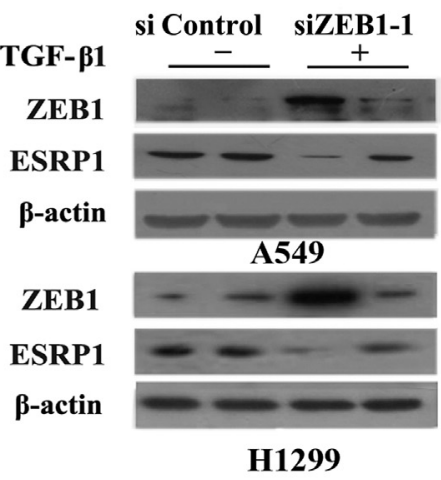

E

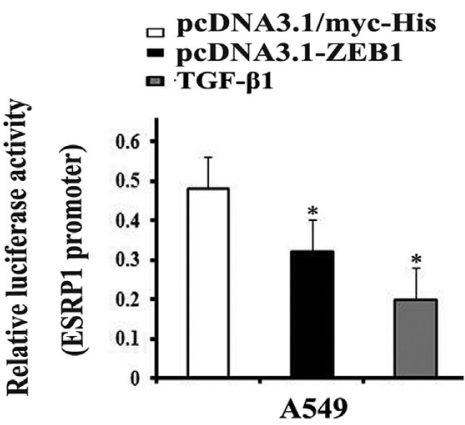

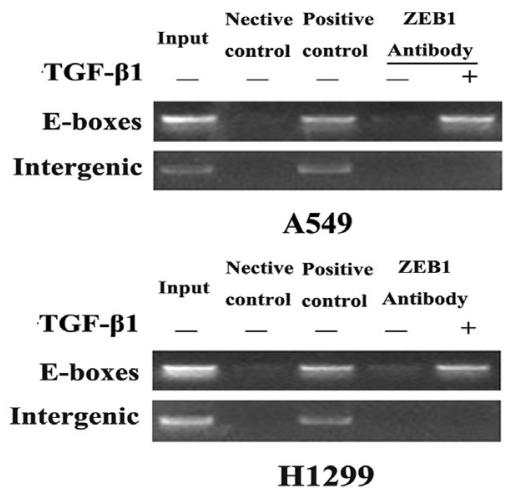

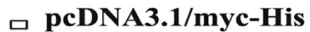
- pcDNA3.1-ZEB1

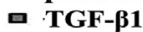
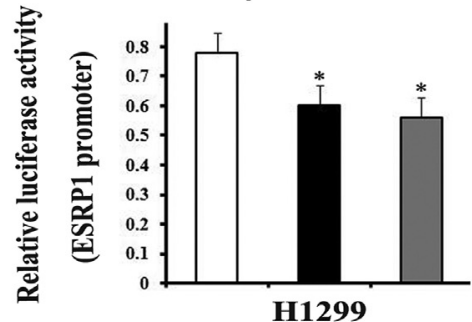

Figure 5 Expression of epithelial splicing regulatory protein 1 (ESRP1) is related to ZEB1 expression. A: Western blot analysis measuring the expression of ZEB1 and ESRP1 in A549 and H1299 cells treated with a control vector and a ZEB1 vector. $\beta$-actin was used as a loading control. B: Western blot analysis measuring the expression of ZEB1 in A549 and H1299 cells treated with three small interfering (si) ZEB1s. $\beta$-actin was used as a loading control. C: Western blot analysis measuring the expression of ESRP1 and ZEB1 in A549 and H1299 cells treated with si control and sizEB1-1. $\beta$ actin was used as a loading control. D: Luciferase analysis in A549 and $\mathrm{H} 1299$ cells. A549 and H1299 cells transfected with the ZEB1 plasmid (pcDNA3.1ZEB1) or the control vector (pcDNA3.1) were cotransfected with pGL4.17-ESRP1. Results were expressed as a fold induction relative to the cells transfected with the control vector (pcDNA3.1) alone after normalization to Renilla activity. E: Chromatin immunoprecipitation analysis in A549 and $\mathrm{H} 1299$ cells. Differences in the expression of Eboxes in the ESRP1 promoter after control or ZEB1 antibody treatment. The PCR products of input were used as a positive control. Data are expressed as means \pm SD of 3 independent experiments $(\mathbf{E})$. ${ }^{*} P<0.05$ versus control. 

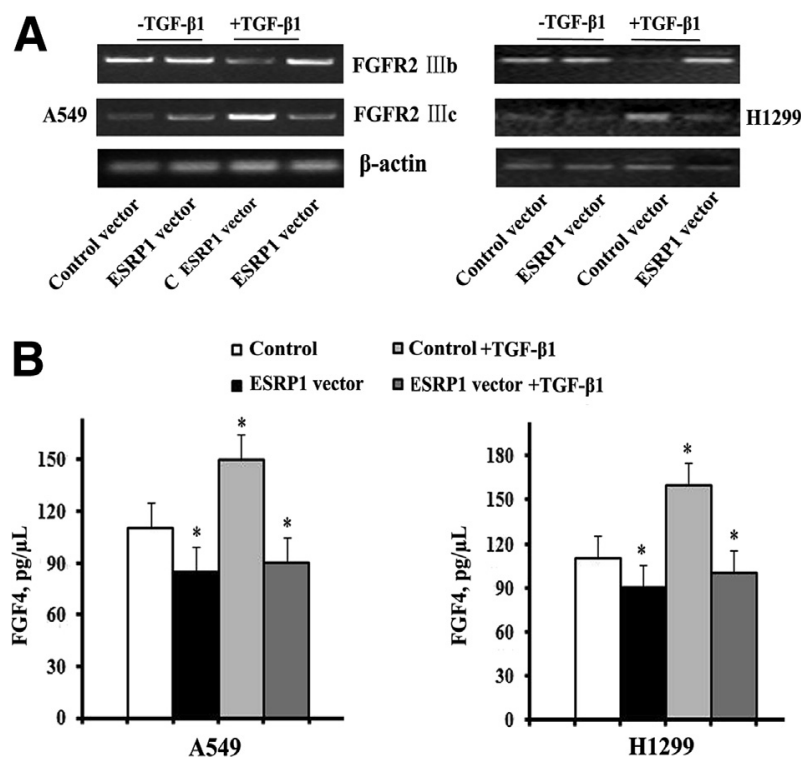

Figure 6 Epithelial splicing regulatory protein 1 (ESRP1) alternative splicing of fibroblast growth factor (FGF) receptor (FGFR) from lung adenocarcinoma cells. A: RT-PCR analysis shows the mRNA level of FGFR2 IIIb and FGFR2 IIIc after ESRP1 vector treatment. $\beta$-actin was used as a loading control. B: Enzyme-linked immunosorbent assay analysis shows the concentration of FGF4 in the cell culture medium supernatant after treatment with the ESRP1 vector. Data are expressed as means \pm SD. ${ }^{*} P<0.05$ versus control.

\section{Discussion}

Several drugs that target growth factors or their receptor tyrosine kinases have been used to treat lung ADC. The genes that typically drive lung ADC are consistent with these treatments and include epidermal growth factor receptor, anaplastic lymphoma kinase (ALK), and ROS-1 proto-oncogene $1 .^{12}$ The ESRPs are an evolutionarily conserved group of proteins with orthologs in nematodes and flies. ${ }^{13}$ ESRP1 binds to the ISE/ISS-3 element and consists of three tandem RNA recognition motifs. ${ }^{14,15}$ The conservation of both structure and function of ESRP1 suggests that a conserved epithelial splicing program originated early during metazoan evolution and plays a profound and essential role in development and tissue homeostasis. ${ }^{16}$

Recent data from several groups have highlighted that ESRP1 is a good predictor of outcome in some tumors, such as pancreatic cancer, colorectal cancer, and oral squamous cell carcinoma. ${ }^{17-20}$ Recent reports have also addressed the plastic role of ESRP1 during cancer progression. ESRP1 became down-regulated in invasive fronts but was reexpressed in neoplastic cells in the lymph nodes, where tumor cells metastasize and colonize. ${ }^{21}$ Our findings indicate that ESRP1 expression in cancer cells adjacent to the tumor center was much stronger than the invasion front. ESRP1 was abundant in primary foci but was weakly expressed in metastatic foci in lymph nodes. The down-regulation of ESRP1 was strongly correlated with TNM stage, metastasis, and lymph node metastasis. The expression of ESRP1 in lung ADC tissue is associated with a prolonged OS and RFS. These results suggest that decreased ESRP1 expression promotes lung ADC progression.

ESRP1 functions as a regulator of alternative splicing events that contribute to the EMT process in tumor progression. EML4-ALK regulates EMT phenotype and represses ESRP1 in non-small cell lung carcinoma. ${ }^{22}$ ESRP1 knockdown impaired E-cadherin up-regulation on ALK inhibition, whereas enforced expression of ESRP1 was sufficient to increase E-cadherin expression. These results indicated that ESRP1 is a key regulator of the EMT phenotype induced by oncogenic ALK in normal and cancer lung epithelial cells. EMT, which enables epithelial cells with a mesenchymal phenotype, plays diverse roles in a series of developmental and physiologic processes. including embryogenesis, wound healing, and stem cell plasticity. ${ }^{23-26}$ A series of transcription factors that control the expression of proteins involved in cell polarity, cell-cell adhesion, and ECM degradation also orchestrate the EMT. ZEB1, an E-box transcriptional repressor, is known to induce EMT and suppresses a suite of epithelial genes during cancer progression. ZEB1 inhibits the expression of epithelial genes central to adhesion and epithelial polarity. ${ }^{27}$ ZEB1 plays a role in the growth of human bronchial epithelial cells and in promoting the tumorigenicity of lung cancer cell lines. ${ }^{28}$ In addition, in human bronchial epithelial cells, ZEB1 expression directly represses ESRP1, which further leads to increased mesenchymal-type splicing of CD44. Accumulating evidence has suggested that ZEB1 appears to correlate with the down-regulation of ESRP1 during TGF- $\beta$-induced EMT. Here, we describe that the up-regulation of ZEB1 was coupled to the suppression of ESRP1 expression in A549 and H1299 cells. Knockdown of ZEB1 by siRNAs was sufficient to restore the expression of ESRP1 in TGF- $\beta$-treated cells. To determine the details of how ZEB1 repressed ESRP1 expression, we performed an analysis of promoter activity in the A549 and H1299 cells with the promoter fragments of ESRP1 inserted into the pGL4.17 plasmid. A chromatin immunoprecipitation assay was used to determine whether ZEB1 binds the ESRP1 gene promoter. Our study found that ZEB1 bound to the ESRP1 promoter and inhibited its transcriptional activity, suggesting that ZEB1 could regulate ESRP1 transcription during the EMT.

A microarray analysis was subsequently performed to determine the gene expression profile after the overexpression of ESRP1. This was mainly done to identify the genes that may be involved in cancer cell invasion and progression after the increase in ESRP1. Metastasis is a continuous process that is accompanied by the translocation of tumor cells from a primary location to more distal sites and allows tumor cells to penetrate vessel endothelium and enter into the circulation. The ECM, which represents a key component of the microenvironment, is involved in cell adhesion and signaling through its interaction with different receptors, including CD44 and FGFR. ${ }^{29,30}$ Notably, some of 
A

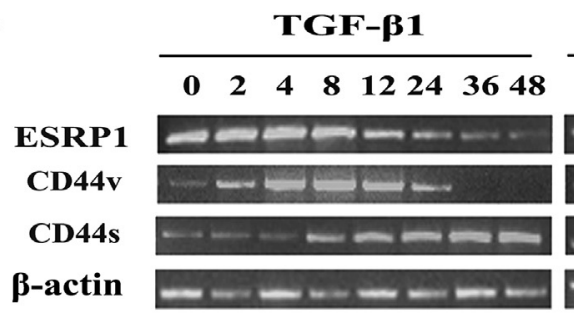

A549

B

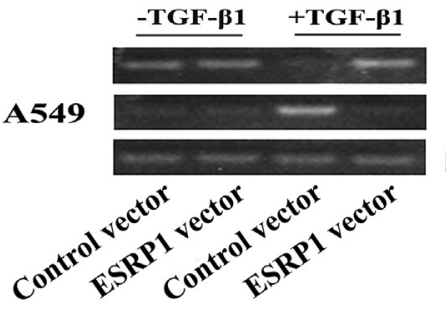

C

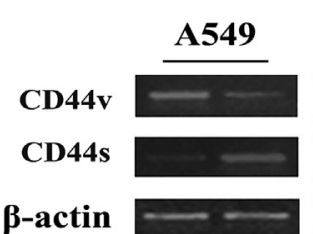

H1299
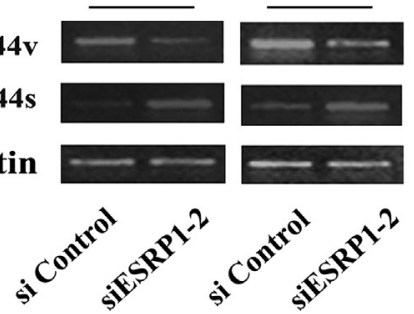

E

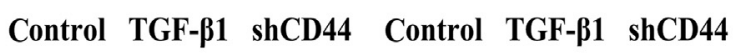
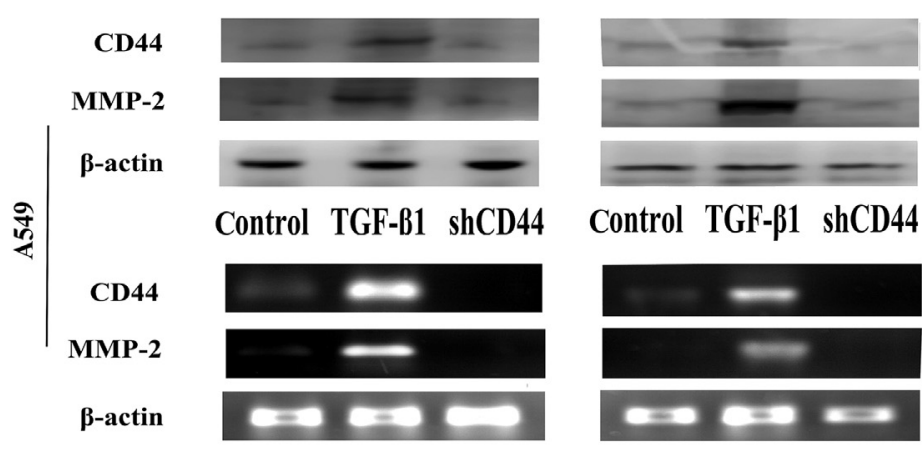

MMP-2

MMP-9

$\beta$-actin

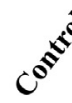

$\mathbf{F}$
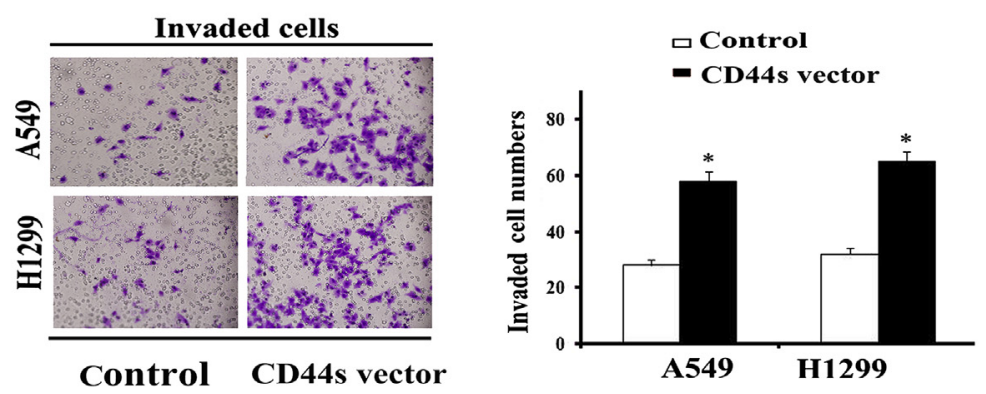

CD44

MMP-2

$\beta$-actin

A549

H1299

H1299

H1299

Figure 7 Epithelial splicing regulatory protein 1 (ESRP1)-mediated alternative splicing of fibroblast growth factor receptor (FGFR) promotes migration and invasion of lung adenocarcinoma cells. RT-PCR analysis shows the mRNA level of ESRP1, CD44v, and CD44s after cells were treated with $5 \mathrm{ng} / \mathrm{mL}$ of transforming growth factor (TGF)$\beta 1$ at different times $(0,2,4,8,12,24,36$, and 48 hours) (A), CD44v and CD44s after cells were transfected with the ESRP1 vector (B), CD44 after cells were transfected with small interfering (si) ESRP1-2 (C), and MMP2 and MMP9 after cells were transfected with control or CD44s vectors (D). $\beta$-actin was used as a loading control. E: Western blot analysis and PCR to detect the expression of CD44 and matrix metalloproteinase (MMP)-2 after treatment with short hairpin CD44 (shCD44). $\beta$-actin was used as a loading control. F: Transwell assay showing invasion of cells transfected with control and CD44s vectors. Data are expressed as means \pm SD of three independent experiments. The axis represents the fold change in the number of cells. ${ }^{*} P<0.05$ versus control. Original magnification, $\times 100(\mathbf{F})$. the gene splice variants regulated by ESRP1 have been implicated in regulating cell adhesion and migration. FGFR IIIb is down-regulated during EMT, whereas FGFR IIIc is up-regulated to confer sensitivity to FGF2, thus inducing an even more aggressive phenotype. ${ }^{31}$ Our team has been working on ESRP1 and its target genes, namely, CD44 and $F G F R$, which are involved in promoting the invasion and metastasis of lung ADC. We explore the role of ESRP1 in the 
invasion and metastasis of lung adenocarcinoma from different aspects. In 2013, ESRP1 expression was measured in $125 \mathrm{ADC}$ tissue samples, and high ESRP1 expression was found to be a prognostic indicator for favorable outcome. Next, the importance of ESRP1 in the process of EMT in lung ADC was explored. The co-localization of CD44 and epidermal growth factor receptor was found to play a role in promoting the induction of EMT. ${ }^{32}$ FGF4, but not FGF7, induces EMT and promotes proliferation, migration and invasion, and colony initiation in A549 and H1299 lung ADC cell lines. More importantly, FGF4 induces EMT via enhancement of store-operated calcium entry in lung ADC cells. ${ }^{33}$ CD44 was identified as one of the many genes that ESRP1 targets for alternative splicing. This cell surface protein is a major marker for stem-like cancer cells and has been implicated in a variety of physiologic processes in addition to cancer cell invasion and metastasis. Therefore, it is necessary to explore the effect of ESRP1 and CD44 on the EMT. In the present study, the data further suggested that that overexpression of CD44s in A549 and H1299 cells promotes invasion and that these changes are accompanied by increased expression of MMP-2.

Studies designed to elucidate the effects of CD44s expression on other EMT-associated signaling pathways, such as PI3K/AKT and ERK, and the novel mode of regulation of EMT on alternative splicing are currently in progress. More importantly, the data presented in this study indicate that the transcription factor ZEB1 regulated the down-regulation of ESRP1 during TGF- $\beta 1-$ induced EMT. The underlying molecular mechanisms that trigger ESRP1 loss and subsequent activation of EMT have not been completely elucidated. This analysis of ESRP1 and its role in EMT may offer new options for novel cancer therapeutic strategies to target the EMT.

In summary, the findings of the current study demonstrated that the inhibition of ESRP1 could effectively retard the growth of lung ADC cells. Furthermore, reduced ESRP1 expression was associated with better clinical responses. Moreover, the switching from CD44v to CD44s by ESRP1promoted alternative splicing increases the invasion of lung ADC cells, indicating that ESRP1 plays an important role in the development and progression of lung ADC.

\section{References}

1. Fang W, Xiang Y, Zhong C, Chen Q: The IASLC/ATS/ERS classification of lung adenocarcinoma-a surgical point of view. J Thorac Dis 2014, 6(Suppl 5):S552-S560

2. Masuda A, Takeda J, Ohno K: FUS-mediated regulation of alternative RNA processing in neurons: insights from global transcriptome analysis. Wiley Interdiscip Rev RNA 2016, 7:330-340

3. Witten JT, Ule J: Understanding splicing regulation through RNA splicing maps. Trends Genet 2011, 27:89-97

4. Warzecha CC, Carstens RP: Complex changes in alternative pre-mRNA splicing play a central role in the epithelial-tomesenchymaltransition (EMT). Semin Cancer Biol 2012, 22:417-427

5. Dutertre M, Vagner S, Auboeuf D: Alternative splicing and breast cancer. RNA Biol 2010, 7:403-411
6. Dittmar KA, Jiang P, Park JW, Amirikian K, Wan J, Shen S, Xing Y, Carstens RP: Genome-wide determination of a broad ESRP-regulated posttranscriptional network by high-throughput sequencing. Mol Cell Biol 2012, 32:1468-1482

7. Warzecha CC, Sato TK, Nabet B, Hogenesch JB, Carstens RP: ESRP1 and ESRP2 are epithelial cell-typespecific regulators of FGFR2 splicing. Mol Cell 2009, 33:591-601

8. Thiery JP: Epithelial-mesenchymal transitions in cancer onset and progression. Bull Acad Natl Med 2009, 193:1969-1978. discussion 1978-9

9. Warzecha CC, Jiang P, Amirikian K, Dittmar KA, Lu H, Shen S, Gu W, Xing Y, Carstens RP: An ESRP regulated splicing programme is abrogated during the epithelial-mesenchymal transition. Embo J 2010, 29:3286-3300

10. Brown RL, Reinke LM, Damerow MS, Perez D, Chodosh LA, Yang J, Cheng C: CD44 splice isoform switching in human and mouse epithelium is essential for epithelial-mesenchymal transition and breast cancer progression. J Clin Invest 2011, 121:1064-1074

11. Reinke LM, Xu Y, Cheng C: Snail represses the splicing regulator epithelial splicing regulatory protein 1 to promote epithelialmesenchymal transition. J Biol Chem 2012, 287:36435-36442

12. Desai A, Menon SP, Dy GK: Alterations in genes other than EGFR/ALK/ROS1 in non-small cell lung cancer: trials and treatment options. Cancer Biol Med 2016, 13:77-86

13. Horiguchi K, Sakamoto K, Koinuma D, Semba K, Inoue A, Inoue S, Fujii H, Yamaguchi A, Miyazawa K, Miyazono K, Saitoh M: TGF- $\beta$ drives epithelial-mesenchymaltransition throughoEF1-mediated downregulation of ESRP. Oncogene 2012, 31:3190-3201

14. Dominguez C, Fisette JF, Chabot B, Allain FH: Structural basis of G-tract recognition and encaging by hnRNP F quasi-RRMs. Nat Struct Mol Biol 2010, 17:853-861

15. Ishiwata T: Cancer stem cells and epithelial-mesenchymal transition: novel therapeutic targets forcancer. Pathol Int 2016, 66:601-608

16. Ueda J, Matsuda Y, Yamahatsu K, Uchida E, Naito Z, Korc M, Ishiwata T: Epithelial splicing regulatory protein 1 is a favorable prognostic factor in pancreatic cancer that attenuates pancreatic metastases. Oncogene 2014, 33:4485-4495

17. Deloria AJ, Höflmayer D, Kienzl P, Łopateckal J, Sampl S, Klimpfinger M, Braunschmid T, Bastian F, Lu L, Marian B, Stättner S, Holzmann K: Epithelial splicing regulatory protein 1 and 2 paralogues correlate with splice signatures and favorable outcome in human colorectal cancer. Oncotarget 2016, 7:73800-73816

18. Leontieva OV, Ionov $\mathrm{Y}$ : RNA-binding motif protein $35 \mathrm{~A}$ is a novel tumor suppressor for colorectal cancer. Cell Cycle 2008, 8:490-497

19. Ishii H, Saitoh M, Sakamoto K, Kondo T, Katoh R, Tanaka S, Motizuki M, Masuyama K, Miyazawa K: Epithelial splicing regulatory proteins 1 (ESRP1) and 2 (ESRP2) suppress cancer cell motility via different mechanisms. J Biol Chem 2014, 289:27386-27399

20. Strausberg RL, Zhao Q: Altered expression and splicing of ESRP1 in malignant melanoma correlates with epithelial-mesenchymal status and tumor-associated immune cytolytic activity. Cancer Immunol Res 2016, 4:552-561

21. Hayakawa A, Saitoh M, Miyazawa K: Dual roles for epithelial splicing regulatory proteins 1 (ESRP1) and 2 (ESRP2) in cancer progression. Adv Exp Med Biol 2016, 925:33-40

22. Voena C, Varesio LM, Zhang L, Menotti M, Poggio T, Panizza E, Wang Q, Minero VG, Fagoonee S, Compagno M, Altruda F, Monti S, Chiarle R: Oncogenic ALK regulates EMT in non-small cell lung carcinoma through repression of the epithelial splicing regulatory protein 1. Oncotarget 2016, 7:33316-33330

23. Guarino M, Rubino B, Ballabio G: The role of epithelial-mesenchymal transition in cancer pathology. Pathology 2007, 39:305-318

24. Kalluri R, Weinberg RA: The basics of epithelial-mesenchymal transition. J Clin Invest 2009, 119:1420-1428

25. Dai J, Qian C, Su M, Chen M, Chen J: Gastrokine-2 suppresses epithelial mesenchymal transition through PI3K/AKT/GSK3ßsignaling in gastric cancer. Tumour Biol 2016, 37:12403-12410 
26. Le Bras GF, Taubenslag KJ, Andl CD: The regulation of cell-cell adhesion during epithelial-mesenchymal transition, motility and tumor progression. Cell Adh Migr 2012, 6:365-373

27. Bojmar L, Karlsson E, Ellegård S, Olsson H, Björnsson B, Hallböök O, Larsson M, Stål O, Sandström P: The role of microRNA200 in progression of human colorectal and breast cancer. PLoS One 2013, 8:e84815

28. Larsen JE, Nathan V, Osborne JK, Farrow RK, Deb D, Sullivan JP, Dospoy PD, Augustyn A, Hight SK, Sato M, Girard L, Behrens C, Wistuba II, Gazdar AF, Hayward NK, Minna JD: ZEB1 drives epithelial-to-mesenchymal transition in lung cancer. J Clin Invest 2016, 126:3219-3235

29. Berrier AL, Yamada KM: Cell-matrixadhesion. J Cell Physiol 2007, 213:565-573
30. Legate KR, Wickstrom SA, Fässler R: Genetic and cell biological analysis of integrin outside-in signaling. Genes Dev 2009, 23: 397-418

31. Shirakihara T, Horiguchi K, Miyazawa K, Ehata S, Shibata T, Morita I, Miyazono K, Saitoh M: TGF- $\beta$ regulates isoform switching of FGF receptors and epithelial-mesenchymal transition. EMBO J 2011, 30:783-795

32. Li L, Qi L, Liang Z, Song W, Liu Y, Wang Y, Sun B, Zhang B, Cao W: Transforming growth factor- $\beta 1$ induces EMT by the transactivation of epidermal growth factor signaling through HA/CD44 in lung and breast cancer cells. Int J Mol Med 2015, 36:113-122

33. Qi L, Song W, Li L, Cao L, Yu Y, Song C, Wang Y, Zhang F, Li Y, Zhang B, Cao W: FGF4 induces epithelial-mesenchymal transition by inducing store-operated calcium entry in lung adenocarcinoma. Oncotarget 2016, 7:74015-74030 